International Journal of

Advanced Science and Convergence

\title{
Mini Industrial Robotic Arm (MIRA) Learning Package
}

\section{Kengie E. Merenciano, $\mathbf{P h D}^{1}$}

${ }^{1}$ Bicol University College of Industrial Technology, East Campus Legazpi City, Philippines

\begin{abstract}
Background/Objectives: This study was conducted for the purpose of designing and evaluating the MIRA Learning Package as an alternative learning tool and a robotic simulation technology solution in providing a set of experience to facilitate the student's learning development experience for STEM Education. Methods/Statistical analysis: The study used the Descriptive and the Design methods of Research. The Design method was used in the construction of a functional prototype, designed specifically to serve as an industrial-like robotic manipulator training kit for students' simulation exercises. Findings: Descriptive method with the use of a questionnaire was used in the analysis of the data gathered. The analysis of data revealed the findings that the Mini-Industrial Robotic Arm (MIRA) Learning Package is an innovative educational platform aimed at providing diverse learning experiences to facilitate student's acquisition of knowledge, skills and attitude for the design, analysis, application and operation of a robot arm. Improvements/Applications: Instructional Manual serves as the students' guide in learning the concept of robotics and its application in other STEM related subjects.
\end{abstract}

\section{Index Terms}

Automation, Industrial Robotic Arm, Mechatronics, Robotics, STEM Education,

Corresponding author : Kengie E. Merenciano, PhD

iam_kengie@rocketmail.com

- Manuscript received July 22, 2019.

- Revised August 23, 2019 ; Accepted September 20, 2019.

- Date of publication September 30, 2019.

(c) The Academic Society of Convergence Science Inc.

2619-8150 ( 2019 IJASC. Personal use is permitted, but republication/redistribution requires IJASC permission. 


\section{INTRODUCTION}

Living in a fast-paced world of technology creates an evolution in every aspect of human life today; the necessity to cope up with the modern way of life is of the essence. This evolution has led to a changing cultural ideology and mankind is in a period of rapid technologically driven change. Its prevalence grown in ways we never could've imagined. Technology is changing the way we live and do work, but it's also transforming the way we learn. Education is one which should adapt to the changes so as not to risk being left behind. But how do we adapt education so that it can equip people to do the types of work needed in the future? The emergence of new technologies pushes educators to understanding and leveraging these for classroom use and at the same time observes how these technologies continue to take shape. From an instructional perspective, this is definitely one of the great challenges imposed to every educator, on how to teach students to learn and prepare them in the future; the fact that though students of today may not be different from those of the past, but the generation of today experience the world differently.

Apparently, globalization seemed to be allencompassing, affecting all areas of human life, and that includes education. In the 21 st century, education systems deal with the two-fold challenge of providing students with the new knowledge, skills and values needed to be competitive in a global market while at the same time producing graduates who are responsible adults, good citizens both of their country and of the world. A country's vision of inclusive growth and development entails investment in human capital, particularly through the provision of quality basic education, competitive technical vocational skills training, and relevant and responsive higher education. Technology Education and training in the Philippines particularly the industrial, technical and vocational education have gone a long way in addressing the manpower needs of the developing economy. It has grown in step with the country's socio-economic development in terms of plans, programs and resources. ${ }^{1}$ The world in this 21 st century is impacted by rapid changes such as digitization, globalization, trade liberalization, and the environmental revolution. In the Philippines, proponents argue that industrialization and the emergence of automation and high technology more than justify the need to offer of undergraduate degree programs on industrial technology. This implies the significant role of education in the economic growth and nation building.
But looking at the country's educational system at present, it continues to turn out college graduates whose training and skills are not attuned to the needs of the labor market both at home and abroad. In the Philippines, youth joblessness and the root of the crisis lies mainly outside education and training sector, the inadequacy of many education and training systems in responding to these challenges has been obviously noted. We often find a considerable discrepancy between the output of graduates in different specializations and the absorptive capacity of the labor market leading, in turn, to unemployment and under-employment of certain types of graduates. In qualitative terms, questions are being raised as to whether the content and performance of systems of higher education are able to meet the changing needs of society, including the new and changing methods of production in the labor market.

The three most important sectors of society that give direct input to the improvement of the quality of education are the academe (institutions), the government, and the industries (both public and private companies). Some government institutions, such as the Commission on Higher Education (CHED) and the Department of Education (DepEd), are directly involved in upgrading the curricular programs of learning institutions. They oversee and control the operations of schools, colleges and universities.

The Philippine government has its means of coping with the immense challenges brought about by this Globalization and has been keen on policy reforms in the educational sector especially in basic and higher education. One of the most promising steps is the implementation of the K-12 curriculum. The law seeks to produce more competitive global Filipino youth through the implementation of the $\mathrm{K}$ to 12 program in basic education. It also aims to equip the youth with 21 st-century skills and mindsets prior to high school graduation. By adding two years to secondary education and developing a more comprehensive basic education curriculum, the government expects to better prepare the youth for employment, entrepreneurship, or higher education both in the country and overseas. ${ }^{3}$ The program intends to provide time for students to consolidate acquired academic skills and competencies. The curriculum will allow specializations in science and technology, music and arts, agriculture and fisheries, sports, business and entrepreneurship.

It is on this premise that there is a need to address this concern even before it actually happens and escalate into uncontrollable dimension. Nonetheless, 
the researcher would like to address the problem by introducing the study Development and Validation of Mini-Industrial Robotic Arm (MIRA) Learning Package as an instructional innovation in teaching technology courses which aims to introduce a new aid for teaching and facilitate learning for students to better appreciate the importance of robotics. This will be made on the note of demonstrating lessons relative to robotic manipulator kinematics using an intelligent distribution board base frame and an embedded system for control, how it functions and to actually present the real sequence that makes every device, machines and the like work. However, in order to accomplish this task, a student needs first to be familiar with the concept of a robotic arm as an image of industrial automation and process control which would serve as guide in constructing a functional sequence and manipulation, observed during simulation. A programmable microcontroller with open source software will serve as the processor or the brain or the command to be followed in order to achieve a desired outcome. It is basically a visual representation of the process, since it is a control that executes each step with a sequence determining its angle and degrees of freedom arranged beforehand. The skills that the student would develop with the use of this device play an important role when they go out of the perimeter of the school for their jobs. They would have an edge in analyzing sequence in the machine, and at the same time they would find it easy to analyze and later troubleshoot problems.

It has been established in preceding literature that robotics educational/training improved the creativity level of students. This study introduced an educational robotic arm for the academic community particularly the students, teachers, and school administrators. This study would provide them to have personal insights on the real physical or dynamical systems. For the teachers, this robot technology will help introduce new concepts and techniques in teaching students in secondary level. It will also make teaching-learning process a pleasant experience for both the teacher and the student, thus making it educationally rewarding. The integration of this study would help the academic community understand the importance of robotics as part of the curriculum. With the application of robotics, it will increase the level of student attentive learning, comprehension, as well as enthusiasm in the classroom. The field of robotics is not only fun and challenging; it is also in-demand in the professional world.

\section{STATEMENT OF THE PROBLEM}

This study aimed to design and construct a Mini Industrial Robotic Arm (MIRA) Learning Package as an innovative STEM pedagogical device with an instruction manual that lets one control a robotic arm with limitless possibilities and the most intuitive interaction bringing the best of its efficiency for teaching robotics in technology courses. Specifically, this study sought answers to the following questions:

1. What Mini-Industrial Robotic Arm (MIRA) Learning Package may be developed as an instructional innovation in teaching technology courses with the following components:
a. Training Kit;
b. Instruction Manual?

2. What Pedagogical principles were applied in developing the lessons in the Mini Industrial Robotic Arm Learning Package?

3. What technical competencies may be developed among the learners using the Mini Industrial Robotic Arm Learning Package?

4. How valid and useful is the Mini Industrial Robotic Arm Learning Package in terms of:

a. Technical aspects;

b. Pedagogical aspects?

5. How can the Mini Industrial Robotic Arm Learning Package be improved?

\section{RESEARCH DESIGN AND METHODOLOGY}

The use of robotics in education benefits STEM learning and how teachers can get started with a robotics program in schools. In this study, students will develop their building and programming skills teamwork, and presentation skills, as well as touch on STEM subjects school students using the MiniIndustrial Robotic Arm Learning Package as a programmable reconfigurable robot, to observe and learn abstract physics concepts and to perform different designed activities.

Every discovery or developmental study has its own bases which are necessary in the interpretation and analysis of that project; thus this study has been conceived using the following theories:

The successful introduction of an educational innovation in school settings is not just a matter of access to new technologies. Technology alone cannot affect students' minds and cannot act directly on learning. Appropriate educational philosophy, curriculum and learning environment are some of the important factors leading any educational innovation to success. Constructionism is a student-centered learning theory that emphasizes discovery learning, 
where students are encouraged to work with tangible objects in the real world and use what they already know to gain more knowledge. ${ }^{4}$ The point is to make the process of thinking and learning visible and to allow for a more process-oriented engagement with an idea via construction and deconstruction. Under constructionism, teachers take a backseat role as facilitators of student learning instead of giving lectures or step-by-step instruction. The role of the teacher is to create the productive context for learning, including material organization, scaffolding, consulting, collaboration and anticipating forthcoming needs of each student. Teaching is subordinate to learning and the teacher is available to seize teachable moments and collaborate with students, rather than direct activity.

Educational robotics is introduced as a powerful, flexible teaching/learning tool stimulating learners to control the behavior of tangible models using specific programming languages (graphical or textual) and involving them actively in authentic problemsolving activities. In the use of robotics, we can see a parallel transition from black box situations of preprogrammed pre-fabricated robots, aimed for the workplace, to white box designs, where children can construct and program robots from scratch.

The Jean Piaget's constructivist approach to learning differs from the traditional teaching concepts mainly in the way of a different understanding of the relationship among activities of teachers and students and it shifts the responsibility for acquiring knowledge closer to the person of a pupil or a student. Students themselves work their own way to knowledge while the teachers are their guides, mentors and organizers of activities. Such a shift of paradigm and of the role of stakeholders is typical for a teaching, based on the constructivist theory. ${ }^{5}$ According to this theory; each student actively constructs their knowledge based on information and experience, which they are gradually acquiring during their life. This view is relevant to the theory of constructionism of Seymour Papert, who identifies series of following practical activities, leading to a real product attractive for the pupils or students, as the most efficient way how to construct their knowledge. For the educational exploitation of technologies, the theories of constructivism and constructionism are particularly beneficial. It is exactly this sphere, where the students very often focus on the practical implementation of various activities, resulting in a specific product, and where they create their own knowledge. The condition for a successful running of the conceived constructivist teaching is a good organizational background of the teacher, based on the knowledge of all aspects of the concept. In training of the future teachers for implementing educational robotics in engineering and science subjects it is therefore understandable to develop approaches particularly relevant to the concept of constructivism. Robotics and constructivism are the fields of science which interest many experts from various specialized institutes in motherland and abroad. However, the study is not directed into these separate, specific areas. It observes a realm still relatively ignored the educational robotics in the context of the constructivist approach - that is an area of applied robotics into education which links to the constructivist theory. Robots are not only built on advanced technology but they also provide a tangible and physical representation of learning outcomes: a valuable aspect of employing them in education.

In like manner, the Theory of Technology Transfer as introduced by Lambright, Yard Woor and Orme which is about the application of scientific knowledge to the practical solution of the problem, connected another chain. ${ }^{6}$ The researcher made use of the practical knowledge learned and incorporated those principles in the study.

The cited theories displayed another link to the Theory of Combination authored by Osborn. This Osborn theory of Combination deals with the systematic convergence of two or more items, ideas or design in an attempt to come up with a new function, or with the purpose of improving the original function. ${ }^{7}$ The concepts behind this theory are applied to the present undertaking in terms of selecting various components of different functions and combining those to one for a new device with special purpose. It also aimed to further improve the studies in the past. The availability in the locality of the materials to be used inspired the researcher more. The framework can be shown Figure 1 as the Theoretical paradigm of the study.

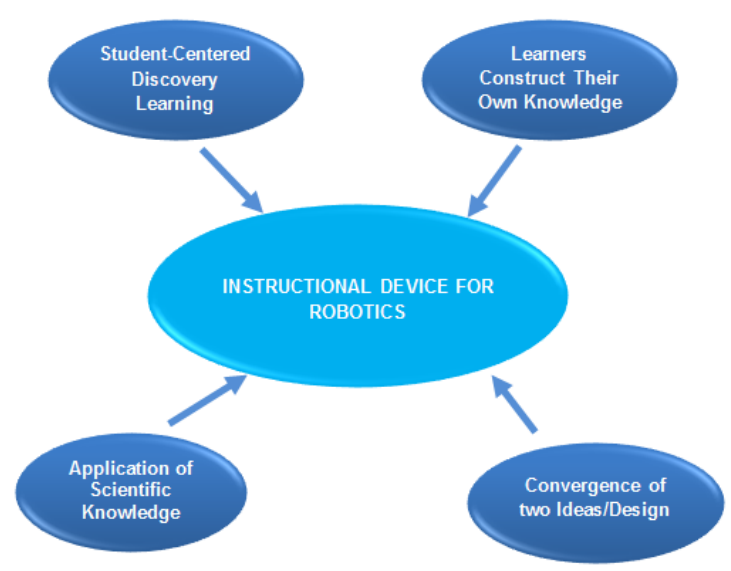

Fig. 1. Theoretical Framework 
This study aims to design and develop a device which is functional as an instructional training kit for robotics that would provide a set of experience to facilitate the student's development of knowledge, skills and attitudes for the design, analysis, application and operation of robots. Employed in this study is the mixed methodology of research, a blend of quantitative and qualitative methods.

The quantitative method through the concept of Research and Design1 was used to be able to make and come up with a device that will serve some purpose. Through this method, findings were generated and used to validate a certain output. Primarily, its appropriateness to the concern of this study is highly beneficial. Research and Design Method aided the researcher to make the desired prototype which was then subjected to testing as to its performance; with some developments made as a unique device compared to the other existing devices made by other researchers.

Furthermore, Qualitative research was also used using Focus Group Discussion (FGD) and interview from pedagogical experts (academic representatives from Philippine Science High School and Department of Education) who provided feedback on the possible approaches, strategies, learning models and methodologies appropriate for the learning package as an instructional material in supporting robotics instruction covering the four STEM disciplines. Documentary analysis was used to determine the capability of the kit as a learning tool. The descriptive survey method was used to primarily obtain the necessary data needed to determine the validity of the learning package in terms of its technical and pedagogical aspect.

The validity of the MIRA Learning Package as an innovative instructional device and as a teaching resource material was assessed by the researcher through documentary analysis, focus group discussion and interview from the experts. The evaluation as to its Technical and Pedagogical Aspect were determined with the use of a questionnaire as the instrument. Technical aspect is defined in this study as the practical use of the device with respect to its operation as an instructional device in aiding instruction specifically on topics which exhibits robotics kinematics and control functions; whether it functions as desired like during simulation. Further, included also in the context of the device' pedagogical aspect is its ability to perform really its purpose of demonstrating the lessons and differentiated instruction that would facilitate easy understanding of the topics found specifically in a subject matter in secondary level.

\section{V.The Mini- InduSTRIAL RobotiC ARM (MIRA) Learning PACKage}

The Mini-Industrial Robotic Arm (MIRA) Learning Package is an innovative educational platform using robotics a new avenue for pedagogy in engaging and stimulating students' interest and achievements in STEM related subjects. This instructional innovation aimed at providing diverse learning experiences to facilitate student's acquisition of knowledge, skills and attitudes for the design, analysis, application and operation of a robot arm. This educational robotics is a new medium of forming the STEM thinking in younger generations, developing their interest in technical creativity, focusing on opting for the engineering professions and working specialties. This technology solution will provide students with exciting, large, fully functioning robotic arm to explore robot kinematics and programming that will bridge the skill gap in preparing 21st century learners to be skilled workforce in the future.

The MIRA Learning package consists of two significant components; a. the MIRA Training kit and $\mathrm{b}$. Instruction manual. This robotic arm simulator can be manipulated using various modules and control systems for education and training with maximum transfer to industrial practice accompanied by an instruction manual that serves as guide for teachers in assisting students to meet the expectations for learning the concept of robotics and manipulating this industrial like robot arm using the training kit.

Designing and developing the Mini-Industrial Robotic Arm (MIRA) Training Kit were the most critical phases of the study. The design ensured the accurate dimension and details of the materials and precise computations of the values on the parts of the components. The other concerns of the researcher at this stage was whether the system would function as planned. Industrial experience, seminars and trainings attended and an in depth study on robotics lead the researcher in developing this STEM instructional device.

Guided by its diagram, this device was constructed following the series of blocks each of which constitute specific function. Figure 4 shows the process flow on how the mini industrial robotic arm works starting with program creation by coding it in the Arduino Integrated Development Environment (IDE) software. Next was to compile and upload the code from the software. If the uploaded sketch file does not work to simulate the robot, there's a need to take a second look on the code and modify its coding. Once the code is 
modified, compile and reupload the sketch file then perform the program task by using the module/kit to control the robot depending on the uploaded code and simulate the system as far as checking of the robot motion perform its given task.

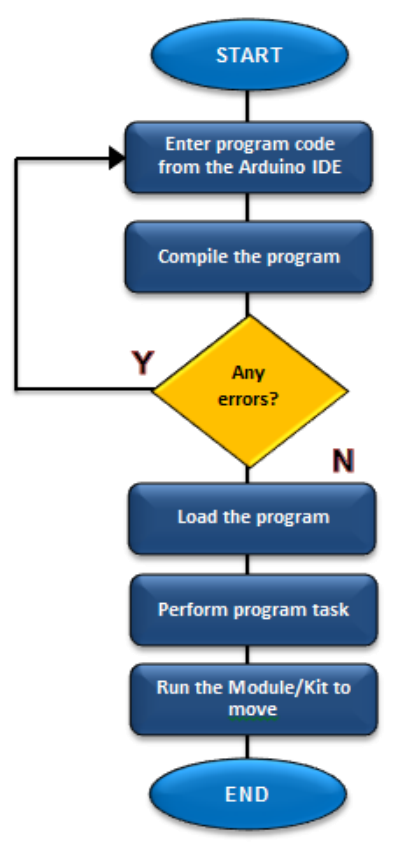

Fig. 2. MIRA Training Kit Algorithm Operation

The four (4) axis desktop robotic assistant is a friendly robotic arm platform developed for makers and educational purposes. The training kit is comprised of; a Mini Industrial Robotic Arm and supported by modules and control systems in order to manipulate the robot kinematics and angular position, using open source technology for robotic education and programming. When used properly, the user would gain the basic information, knowledge and likewise appreciate the complex topics and have it made simple and easy to comprehend. This is an open-source and inexpensive robotic platform fit for technology curriculum or robotics research labs. This technology is a great way to discover robotics designed for scientific and technological learning, initially set a challenge of developing students' programming skills while providing them with versatile and intelligent tool for performing numerous industrial robotics operations. All hardware and electronics are provided along with open source inverse kinematics engines and code examples for this modern industrial robot for the desktop. Figure 5 shows the prototype design of the instructional device.

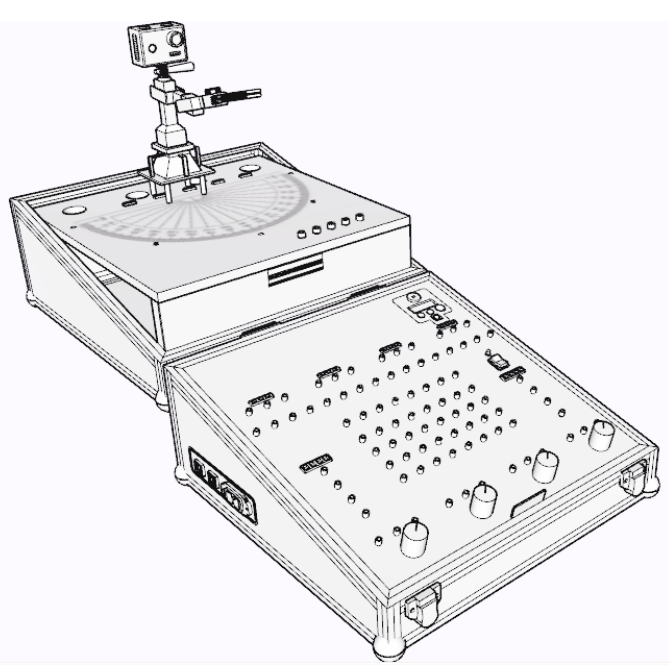

Fig.3. MIRA Training Kit Design

The Technical aspect for this study refers to the discussion of the design, mechanism and operation of the instructional device. The salient features of this device are one of the essentials considered by the researcher since this factor responds to the technicalities and basic structure of the proposed study. The variables considered under technical aspect were on the instructional device structural and mechanical design, as well as the programming and sensor control. The data gathered by the researcher were consolidated and computed using the weighted mean in order to have interpretation of the results.

To sum up, the respondents answered the questionnaire as to the experts' validity on the device in terms of technical aspect and the general mean of 4.15 which has an adjectival description of Very Satisfactory was achieved. These four distinct variables were consider in evaluating the structural and mechanical features of MIRA as an instructional device then includes the programming and sensor control which determines the capability of the device to interface using control modules and systems in demonstrating the identified lessons. Each statement has a corresponding weighted mean. Based on the experts' feedback, this instructional device operates as desired based on its design and construction. The device is easy to use and attractive to study robotics making a fun yet challenging environment for learning.

It can be gleaned the summary results of evaluation from the experts concerning the pedagogical aspect of the MIRA learning package. The MIRA Instruction manual was assessed by the experts as reflected in table 14 garnering an overall weighted mean of 4.65 and an adjectival interpretation of outstanding was achieved. This 
result shows that this teaching resource material was made to facilitate the student's development of knowledge, skills and attitudes for the design, analysis, basic application and operation of a robotic arm using microcontroller and programming. The experts provided a positive response on the capability of the manual in teaching robotics and programming and there were some good points observed after the evaluation. The manual provides information sheets which contain background information for each topic and are properly arrange from basic to application as the lesson progresses. The researcher considered the 21 s century skills in identifying deeper learning competencies and skills for learners by developing meaningful lessons in robotics as well its objectives. A number of worksheets have been provided for each lesson. These worksheets allow students to work independently as they include instructions for student to follow. The worksheets also include questions for the students to answer that reinforce and demonstrate their learning. This manual provides activities for students with a working area to quickly test their programs and run experiments during simulation. Assessments used check whether the goals meet the instructional needs in exploring robotics. Project assessments accompanied by rubrics, provide the teachers to monitor the learning progress of the students whether or not they understand course material and provide feedback for developing better instruction to ensure students learn what they need to know in order to meet the learning objectives.

\section{Conclusion}

Based on the findings drawn from the data analyzed, the following conclusions were deduced:

1. The researcher aims to introduce a new aid for teaching and facilitate learning for students to better appreciate the importance of robotics that will bridge the skill gap in preparing 21 st century learners to be skilled workforce in the era of globalization. The Mini Industrial Robotic Arm (MIRA) Learning Package with its training kit and instruction manual were developed as a functional instructional device by virtue of its design and has achieved its purpose as a Robot Arm Training Kit Simulator with the aid of the modules and control systems integrated into the panel distribution board in teaching robotics concepts in STEM related disciplines. The materials used are locally available and the result in constructing the device is cost effective. The lessons found in this MIRA Instruction Manual were beneficial to the students in studying robotics and can be integrated in the secondary curriculum. The ten lessons were clearly stated and designed to meet the needs of individual learners from various skill levels in understanding STEM fields using this learning device.

2. The pedagogical principles and approaches applied in this study aided the researcher in coming up with an innovative instructional technology that will motivate students in studying robotic concepts that can be applied in the secondary curriculum particularly in the STEM related fields.

3. The technical competencies identified in this study define the knowledge and skills that are required in STEM career field in preparing students to be successful in the future.

4. The Mini-Industrial Robotic Arm (MIRA) Learning Package was validated by the experts as an effective instructional device and teaching resource material in robotics.

5. The experts' feedback is useful in further improving the technical aspects of the device as an alternative learning tool in robotics. The experts highly recommended the inclusion of the MIRA Learning package as part of the secondary curriculum.

\section{ACKNOWLEDGMENT}

With all the ups and downs of this endeavor, success is indeed a failure turned inside out - the silver tint of the clouds of doubt. The road towards this completion has been a rocky one but still, this is a manifestation of God's mercy which the researcher experienced from everyone who has made this journey extra momentous. As he have learned the meaning of life while adventurously discovering God's gift, the researcher is gratefully sharing this to all of the kind hearts and witty minds behind the achievement of this study.

To the Bicol University Administration headed by President Dr. Arnulfo M. Mascariñas together with Dr. Amelia A. Dorosan, VP for Administration, Dr. Helen M. Llenaresas, VP for Academic Affairs, Dr. Jennifer T. Barrameda, Human Resource Management and Development Officer, members of The BU Scholarship Committee for granting full scholarship benefit to the researcher to finish this undertaking.

To Dr. Jonathan C. Arroco, Dean of BU College of Industrial Technology and the members of the Local Advisory Committee, for favorably endorsing the researchers' application for study leave.

To Dr. Nicanor B. Balbin, Dissertation Adviser, for his all-out support and never ceasing intellectual comments that helped the researcher to improve this work; likewise for sharing his expertise and for the patience and understanding.

In addition, to the panel of evaluators, - Dr. Lorna M. Miña, Dr. Nora L. Licup, Dr. Marcia 
Corazon P. Rico, Dr. Luis O. Amano and Dr. Edwin L. Mias, chairperson and members of the panel respectively, their erudite comments and suggestions are appreciated to facilitate the improvement of this endeavor. Each of the members of the committee provided extensive personal and professional guidance both scientific research and life in general.

To Sir Sevedeo Malate, Sir Andrew S. Tenorio, Sir Jeavons Pablo Mesia, Sir EJ Marmol Sir Remigio Espares and the heads and personnel of the Philippine Science High School-the respondents and researcher's friends, for the untiring support especially in answering the questionnaires and interview questions amidst hectic schedules.

To his mentors and colleagues from BUCIT whose boundless support helps him grow in wisdom as years are added in his age. The researcher is also hugely appreciative to Prof. Christian C. Calleja, whose insights are instrumental to completing this study; reflective of a product of extensive discussions and went beyond friendship-duty calls.

Similar, profound gratitude goes to Architect David Marvin Jarilla, whose talents contributed to the completion of this study and who taught the researcher the great value of attitude at work.

This work would not have been possible without the help of Mr. Danel Acuña, his research assistant and former student who was also sleepless as he joins the researcher in his late night works to meet the deadline.

Special mention goes to his friends, Rommel, Jeciel, Bryan, Alex, Ralph, Leornz, Tsubs, Dobz, Loren and Richmond for their thoughts, visits, editing advice and being truly friends to count on.

Nobody has been more important in the pursuit of this study than the members of his family. The researcher wish to thank his siblings - Kinley, Kathleen and Klarence for all the support and for giving strength to face all life's challenges and being part of this success.

Most importantly, the researcher would like to thank his late parents, Edwin and Felina whose love and guidance are with him in whatever he pursues. They are his ultimate role models. They have always been his strength to push through all the hardships, and they direct his path so he may always be walking in the right track.

To his dearest one -for the love and infinite support making him feel that he is not alone during the darkest moments of this journey. Words are not enough to describe how amazing person she is, who has been with him all these years and has made them the best years of his life.

To all other people whom he forgot to include, but memories of their kindness will forever be remembered.

And ultimately to God, the source of infinite wisdom and grace that worked in him every day.

"My flesh and my heart may fail, but God is the strength of my heart and my portion forever". Psalm 73:26

\section{REFERENCES}

[1] http://www.dlsu.edu.ph/research/centers/cberd/pdf/bu s_focus/Technological_Vocational.pdf

[2] IndustrialTechnology,http://study.com/directory/categ ory/Engineering/Industrial_Engineering/Industrial_Te chnology.html

[3] Increasing Public Awareness of TVET in the Philippines, A Case Study, http://www.unevoc.unesco.org/fileadmin/user_upload /docs/CS_Philippines_Public_awareness.pdf

[4] Resnick, M. (2008). Sowing the Seeds for a More Creative Society. | Learning \& Leading with Technology December/January 2007-08, International Society for Technology in Education, $18-22$.

[5] Resnick, M. (1995). New paradigms for computing, new paradigms for thinking. Computers and Exploratory Learning. New York, New York: Springer-Verlag.

[6] S. Michael Camp \& Donald L. Sexton. (1992). Technology Transfer and Value Creation: Extending the theory beyond information exchange, https://link.springer.com/article/10.1007/BF02199480

[7] Demokritov, S. O. \& Demidov, V. E. (2008). MicroBrillouin light scattering spectroscopy of magnetic nanostructures. IEEE Transactions on Magnetics, 44(1), 6-12.

[8] Yarwood \& Orme. (1, Oct. 1983). "Design and Technology" (Seven Oaks, Kent) p.6. 